\title{
The Dual Analysis of Adjuncts/Complements in Categorial Grammar
}

\author{
David Dowty \\ Ohio State University \\ dowty@ling.ohio-state.edu
}

\begin{abstract}
The distinction between COMPLEMENTS and ADJUNCTS has a long tradition in grammatical theory, and it is also included in some way or other in most current formal linguistic theories. But it is a highly vexed distinction, for several reasons, one of which is that no diagnostic criteria have emerged that will reliably distinguish adjuncts from complements in all cases - two many examples seem to "fall into the crack" between the two categories, no matter how theorists wrestle with them.

In this paper, I will argue that this empirical diagnostic "problem" is, in fact, precisely what we should expect to find in natural language, when a proper understanding of the adjunct/complement distinction is achieved: the key hypothesis is that a complete grammar should provide a DUAL ANALYSIS of every complement as an adjunct, and potentially, an analysis of any adjunct as a complement. What this means and why it is motivated by linguistic evidence will be discussed in detail.
\end{abstract}

\section{The Starting Points: Initial Intuitions about the Phenom- ena, and a Theoretical Framework to work from.}

\subsection{The Pre-Theoretic Notion of 'Adjunct' vs. 'Complement'}

I will begin with some basic, intuitive, characteristics that have motivated linguists to draw the adjunct/complement distinction over the years, whatever their theory (if any) of these categories differ. That is, we start from common pre-theoretic notions of how adjuncts differ from complements, and proceed to build a formal account that, as first goal, satisfies these:

- Syntax: An adjunct is an "optional element", while a complement is an "obligatory element".

- Semantics: An adjunct "modifies" the meaning of its head, while a complement "completes" the meaning of its head.

To try to spell these out more concretely what these entail, I propose the following restatement of them; I have chosen this particular way of formulating them because it will help us to better see how the theory presented below does satisfy them, but I believe this formulation is still consistent with linguists' pre-theoretic notions. 


\section{- An adjunct is "optional" while a complement is "obligatory":}

- A constituent $Y$ in a phrase $[X Y]$ (or in $[Y X]$ ) is an ADJUNCT if and only if (i) phrase $X$ by itself (without $Y$ ) is also a well-formed constituent, and (ii) $X$ (without $Y$ ) is of the SAME syntactic category as phrase $[X Y]$. ( $X$ is in this case the HEAD of the phrase $[X Y]$.)

- Then, a constituent $Y$ in $[X Y]$ is a COMPLEMENT if and only if (i) $X$ by itself (without $Y$ ) is not well-formed, or else (ii) if it is grammatical, then $X$ standing alone not really have the same category in $[X Y]$ (and does not have exactly the same meaning as it has in $[X Y]$.

The caveat in (ii) is needed to allow for elliptical complements, which this criterion might otherwise class as adjuncts; see more just below.

\section{- An adjunct "modifies" the meaning of its head, while a complement "completes" its head's meaning.}

- If $Y$ is an adjunct, the meaning of $[X Y]$ has the same kind of meaning (same logical type) as that of $X$, and $Y$ merely restricts $[X Y]$ to a proper subset of the meaning/denotation of $X$ alone.

- Where $Y$ is a complement in $[X Y]$, (i) the meaning of $X$ by itself, without $Y$, is incomplete or incoherent.

Else, (ii) $X$ must be understood elliptically — the hearer must imagine/infer some context-dependent or anaphoric meaning of the general kind of $Y$ to "fill in" the semantic slot that $X$ requires semantically ${ }^{1}$. (For example both eat lunch and eat alone are grammatical VPs, but the latter must be understood as "eat something or other", so lunch is a complement, not an adjunct.)

- Also, the same adjunct combined with different heads affects their meaning in the "same" way semantically (e.g. walk slowly vs. write slowly). But the same complement can have more radically different effects with different heads (e.g. manage to leave vs. refuse to leave).

There are, to be sure, a number of well-known problematic cases of adjuncts and complements that don't quite fit these characterizations (for example, intensional adjuncts like utter in utter fool), but I still maintain that these general, pre-theoretic characteristics are the first and most basic properties that a linguistic accounts of adjuncts vs. complements should capture.

\subsection{Categorial Grammar: some preliminaries}

Although the hypothesis of the dual analysis of Complements as Adjuncts could possibly be formulated within several different current grammatical frameworks, it is the theory of Categorial

\footnotetext{
${ }^{1}$ Admittedly, the difference between elliptical complements and adjuncts is hard to establish empirically for certain individual examples. However, we will see later on in this paper why the indeterminacy of some particular examples is in fact just what the dual analysis view predicts.
} 


\section{Dual Analysis of Adjuncts/Complements}

Grammar $^{2}$ (henceforth: CG) that offers a particularly direct and compelling way of implementing this hypothesis: because of the tight connection between syntactic analysis and compositional semantics in CG (which is stronger than in any other current theory), we can show within CG that many of the semantic properties of the adjunct/complement distinction follow directly from the syntactic CG characterization of adjunct/complement (and/or vice-versa).

For this reason, we need to explain some assumptions, familiar within CG for a long time now (cf. (Venneman \& Harlow 1977)), as to how the basic distinction is characterized in that theory; these are stated further below in (2) . But for this, in turn, we first need to review the way categories are named and are combined to form constituents in CG:

a. Standard definitions of syntactic categories: these include both PRIMITIVE CATEGORIES, denoted by simple symbols (usually only these three: $S, N$ (common nouns), and $N P$ ), and COMPLEX CATEGORIES, formed (recursively) from a pair of more basic categories by "/" and "\"; e.g. $S / N P, N P \backslash S, S / S, S /(N P \backslash S)$, etc.)

b. How groups of syntactic categories are put together to form constituents: $A / B+$ $B \Rightarrow A$. "Where $\mathrm{A}$ and $\mathrm{B}$ stand for any categories, a category with a name of the form 'A/B' will combine with a category named ' $\mathrm{B}$ ', to its right, to form a phrase '[A/B B]' of category 'A' ". Cf. a (nearly) equivalent phrase structure rule $A \rightarrow A / B B$ ". (This rule-schema is called the Functional Application Rule Schema, also known as Slash Elimination and as "The L-rule for /".)

Note that where the slash direction is reversed, $(A / B$ vs. $B \backslash A)$ the left-right order in which the two constituents are combined is to be reversed: $B+B \backslash A \Rightarrow A$.

c. Semantic interpretation via the CURRY-HOWARD ISOMORPHISM: ${ }^{3}$ compositional meaning is uniquely and rigidly determined by syntactic structure; the only two possibilities are (semantic) functional application (for Slash-Elimination) and functional abstraction (for Slash-introduction, or "The R-rule for l"). In other words, all other kinds of compositional semantic effects, within a construction, must be attributed to meanings of one or more lexical items in the construction, not to compositional semantic rules specific to the construction. (We can view this as the semantic counterpart of what has been called the "Radical Lexicalism" that CG demands).

d. Categorial Grammar derivations are traditionally conceived of as being built up from the bottom upward; one "combines" two constituents to "result" in a phrase (indicated by the mother node above them in a tree diagram), rather than generating a tree from

\footnotetext{
${ }^{2}$ Since the primary audience for this paper includes readers without familiarity with recent formulations of categorial grammar (or type-logical grammar, as these are called), my presentation of CG here will be deliberately informal and simplified. However, readers with more extensive knowledge of type-local grammar (as in Morrill (1994), Carpenter (1997)) should keep in mind that everything I say here can be (and is intended to be) formulated more precisely. To handle the problems in this short paper, the Associative Lambek Calculus (L) will suffice, and all theorems of $\mathbf{L}$ will hold. (For a language like English, I would ultimately choose a multi-modal system, to be able to treat both hierarchical and "flat" natural language constituents accurately, and to be able to include both wrapping (Dowty 1996) and occasional free word order). Syntactic features, mentioned below, are intended to be formalized by the (very conservative) method of introducing them only on the primitive types; the result is that the number of primitive types is large but still finite, and since no new provision is needed for features in the logical rules (Slash-Elimination and Introduction), the logic of $\mathbf{L}$ remains intact. Although I use quasi-phrase-structure trees here rather than the standard natural deduction or Gentzen derivation, informed and thoughtful readers should have no trouble seeing the implicit formal type-logical treatments behind everything said in this paper.
} 


\section{David Dowty}

the top (or 'root') node downward as in PS grammars. Hence, the category that "dominates" two constituents is called the RESULT CATEGORY. This different viewpoint on derivations does not ultimately make any theoretical difference at all, but I will use this terminology throughout this paper.

\subsection{Complement vs. Adjunct in Categorial Grammar}

Now, we show how a formal but general definition of complement and adjunct can be made in CG, and in a way that generalizes across all kinds of syntactic categories. This distinction is NOT made in terms of phrase-structure configurations. Nor does it mention specific syntactic categories. Rather, the definitions of head, complement and adjunct, are in effect META-CATEGORIAL DEFINITIONS: they use $A$ and $B$ as variables over category names, and the characterization depends on the relationship between the relative form of two category names that enter into a combination. Since both grammatical function and semantic interpretation in CG are fully determined by the form of a category name and the category name it is combined with, it is perfectly natural that these meta-categories are specifiable this way in CG.

(2) a. A Head-Complement Structure is defined in CG as any syntactic combination of two constituents having the form $[A / B B]$ (or else $[B B \backslash A]$ ), where $A$ and $B$ are any categories with the condition that $A$ and $B$ are not the same category: here, $A / B$ is the Head ${ }^{4}$ and $B$ is the complement.

b. A Head-Adjunct Structure is defined in $\mathrm{CG}$ as any combination of two constituents having the form $[A A \backslash A]$ (or else $[A / A A]$ ), where $A$ stands for any category; here, $A$ is the head and $A \backslash A$ is the Adjunct.

\footnotetext{
${ }^{3}$ See (Carpenter 1997) for an exact account of the so-called Curry-Howard Isomorphism

${ }^{4}$ This characterization of Head has been criticized because it appears that certain heads would incorrectly be classed as adjuncts, even if morphological features are taken into account, for example, in:

1. John can help wash the car.

the verb help must agree with its head (can), i.e. must be in a certain morphological form (say, [BASE]). In turn, help governs a complement VP of morphological form [BASE], so its fully specified category is something like

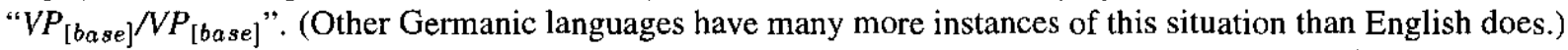

The solution to the problem lies first in distinguishing agreement from government in CG. This can be done by (i) incorporating features into category names (though only on primitive categories, so the logic of $\mathbf{L}$ remains fully intact), and (ii) assigning category membership of many words to a category schema (not just a fully specified category). An item that should agree in all features with its VP head might be assigned to category $V P_{\alpha} \backslash V P_{\alpha}$, where $\alpha$ stands for a whole range of features (finiteness, number, inflectional form) with any feature values for these, as long as the corresponding feature values are the same in both occurrences of $\alpha$. (By taking advantage of this kind of schematization, an account of morphological agreement can be built into the category assignment). A word that agrees with various features on its morphological head but governs a certain feature on its complement (such as help) would then belong to a category like $V P_{\alpha} N P_{\text {[BASE] }}$, indicating that it governs the [BASE] form on its complement but agrees in all feature values on its own head. Specifically, then, we want the definition of "Head" to be sensitive to the lexeme the item belongs to (to use an old-fashioned term), not based on the particular inflectional form of that lexeme that happens to needed in this sentence. HPSG, because of its strongly "lexicalist" approach to morphology, apparently cannot (or chooses not to) make reference in the syntax to the kind of morphological paradigm a word belongs to, but I see no reason why CG cannot take advantage of this possibility. Full details will be given in a later paper.
} 


\section{Dual Analysis of Adjuncts/Complements}

Head-Complement Structure:

$A, B$ any categories, $A \neq B$

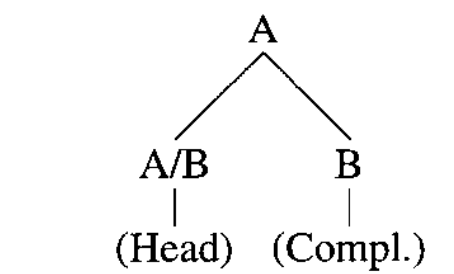

Semantics: Head'(Compl')
Head-Adjunct Structure:

A any category

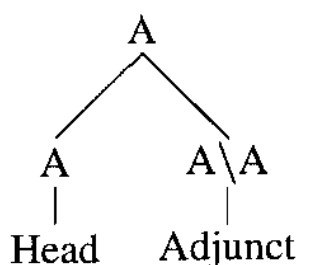

Semantics: Adjunct' $\left(\mathrm{Head}^{\prime}\right)$

For example, all of the cases in (3) fit the characterization of Head-Complement structures: (here, $V P$ is a notational abbreviation for $N P \backslash S$ ),

(3)

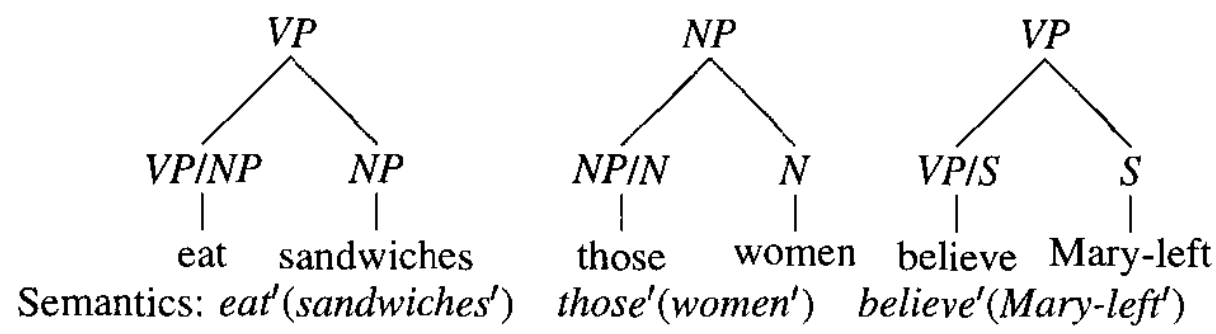

and (4) shows examples of adjunct constructions:

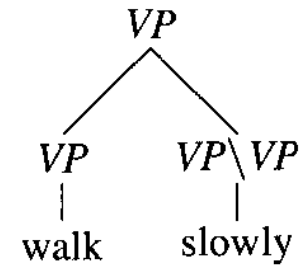

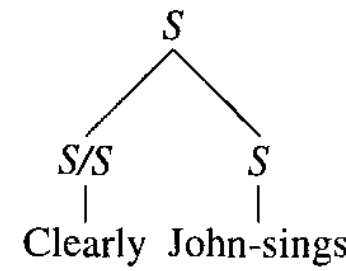

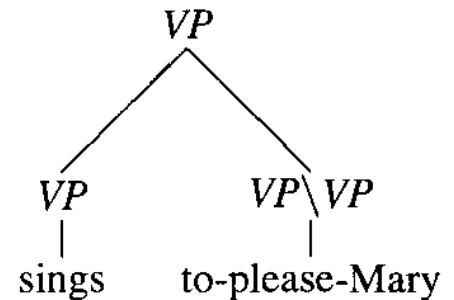

sings to-please-Mary

Semantics: slowly $\left(\right.$ walk $\left.^{\prime}\right) \quad$ clearly $^{\prime}\left(J_{o h n-s i n g s}\right) \quad$ to-please-Mary $\left(\right.$ sing $\left.^{\prime}\right)$

It is immediately clear why "obligatoriness" of compliments is captured: since the category of the head by itself is not the same as the category of [head + complement], the head alone cannot fill the same grammatical slots as the [head + complement] phrase can fill; likewise semantically, the meaning of the head alone is not the same semantic type as that of the phrase, hence the meaning of the head alone is "incomplete" without the complement meaning and cannot yield a meaning of the required semantic type for the phrase as a whole. Conversely, it should be easy to see how it does follow from the characterization of Head-Adjunct structures that adjuncts are "optional" in both syntax and semantics.

\subsection{When a Head has both Complement and Adjuncts}

Two further predictions follow immediately from these characterizations which correspond to old observations about adjuncts vs. arguments: (i) multiple adjuncts (an unlimited number), can accompany the same head (indicated by the dotted line in the diagram), while only a fixed number of complement(s) can accompany a head (viz. just the one (or two, etc.) subcategorized by the particular head), and (ii) when both complement(s) and adjunct(s) accompany the same 
head, the complement must generally be "closer" to the head, with the adjunct(s) "outside" the complement. The reasons for these predictions can be seen from this schematic derivation tree and example:

\section{Both Complements and Adjuncts of the same Head:}

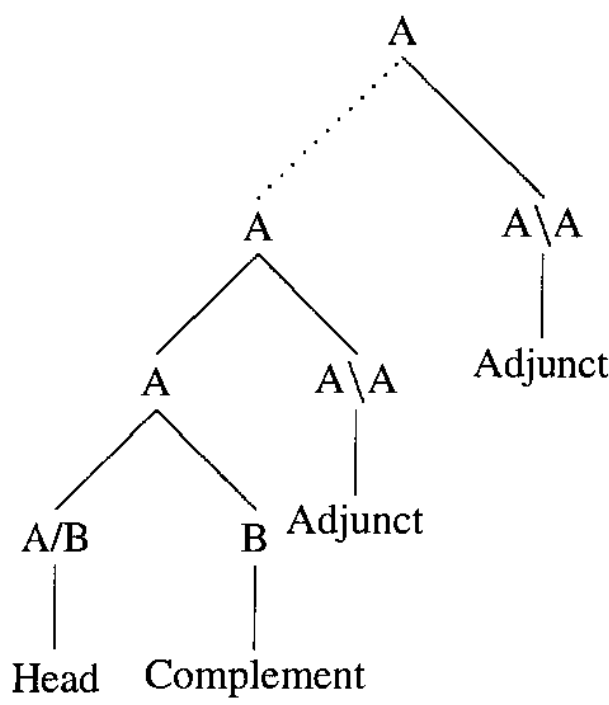

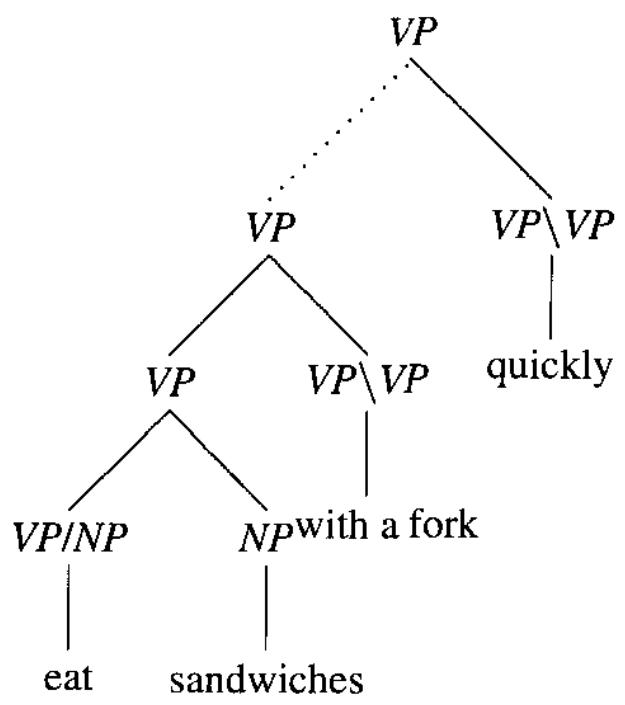

Because the addition of an adjunct to a head leaves the result category the same as the head's category, one can continue to add on more and more adjuncts at will: this is because the highest phrasal category in the tree will always be the same category (here, $A$ ) as the one below it. But the combination of a complement (here $B$ ) with a head $(A / B)$ produces a different result category category from that of the head (result is $A$ ), hence a complement must be added exactly once, never more than once. Also, the adjunct(s) can be added on only after the complement, because the category with which the adjunct can combine is not present until the complement has been added, thus explaining why adjuncts (in this category configuration) occur "outside" complements - and of course the observation that complements typically occur closer to their head than adjuncts do. Similar predictions of course follow from $X$-Bar Theory in phrasestructure-based theories-but only as a result of stipulating a separate $X$-Bar Theory, distinct from phrase-structure proper. The important point here is that these predictions already follow simply from the basic CG theory, together with our definition of adjunct and complement: there is no need for a notion of "X-bars" at all in CG.

\subsection{Subcategorized Adjuncts}

Traditional grammar may have sometimes viewed adjunct and complement as fixed sets of syntactic categories - for example, Adjective and Adverb were considered adjunct categories, once and for all, and Noun (Phrases) were considered complement categories. But more recently it has been recognized that adjectives and even adverbs that are adjuncts in most occurrences do in certain other contexts appear to behave like complements. Some examples are in (6): the verb tower seems to take a locative PP as a complement, and verbs treat and behave take adverbs as complements: 
(6) a. The campanile towers over the Berkeley campus

\#The campanile towers.

b. He always treated me fairly. \#He always treated me. (OK only with different meaning for treat). ${ }^{5}$

c. Johnny behaved badly. \#Johnny behaved. (OK only with different meaning for behave)

The term SUBCATEGORIZED ADJUNCT has been widely adopted for such cases. Notice that the CG account of adjuncts above, in not treating "adjunct" as a fixed set of categories list of categories, does already offer an interesting way of characterizing a subcategorized 'adjunct'. In a head-complement configuration, $[A / B B]$, the complement $B$ can be any category whatsoever, including one that is an adjunct category in other configuration: viz., where $B=C \backslash C$. Also, $C$ can be equal to $A$ here, so that $B=A \backslash A$. This possibility is illustrated in (7), where (7a) is the typical configuration in which $V P \backslash V P$ (the category of (verb-phrase) adverbs) occurs as an adjunct. But ( $7 \mathrm{~b})$ shows the case where an adverb occurs as a complement:

a. normal adjunct structure:

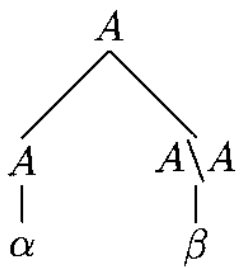

b. Head-Complement structure with "subcategorized adjunct":

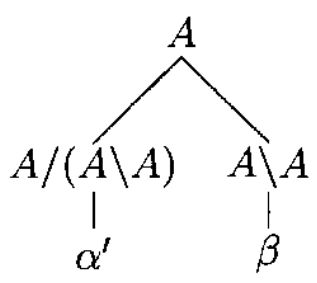

\section{Example:}

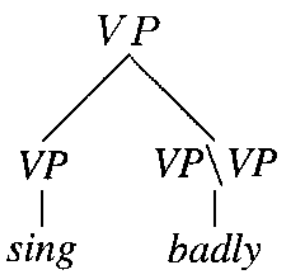

Example:

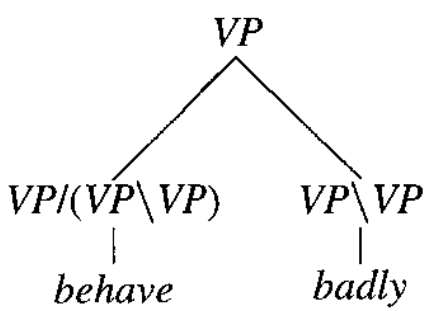

In fact, we now adopt the category configuration in (7b) as our definition of SUBCATEGORIZED ADJUNCT ${ }^{6}$ (Note that in a head category name, of the form $A / B, B$ is in effect the category of complement that the head is subcategorized for. So just as $V P / N P$ is a verbal head

\footnotetext{
${ }^{5}$ To be sure, He always treated me can in fact be a grammatical string, but in the grammatical reading of it treat does not have the same meaning as it does in treat me fairly, and the same is true for behave (badly).

${ }^{6}$ In most formal versions of categorial grammar, including the NON-ASSOCIATIVE LAMBEK CALCULUS (NL), the Associative LAMBEK CAlCulus (L) (cf. Moortgat 1998), and Combinatory Categorial Grammar (Steedman 1996), a structure like (6b) is automatically available as an alternative syntactic structure for (6a) (and with the same meaning), due to the rule (or theorem) of Type Raising. We do not want such type raisings to count as subcategorized adjuncts, so we need to add a caveat to our definition: an expression $\alpha$ in category $A / B$ is a head in the combination $[A / B B]$ only when $\alpha$ does not also occur in some simpler category (i.e. is not a result
} 
subcategorized for a NP complment-i.e. it is a transitive verb-so $V P /(V P \backslash V P)$ is a verbal head subcategorized for an adverb complement.)

\section{The Dual Analysis Hypothesis}

\subsection{A Case Study: Locative vs. Dative To}

Perhaps the best way to begin to see motivation for the dual analysis is to examine a (very) familiar case where the same prepositional phrase has different meanings with different heads: English PPs headed by to which sometimes have directional, sometimes non-directional meaning. The directional readings, which are systematic and perfectively compositional are exemplified in $(8 \mathrm{a})-(8 \mathrm{c})$ :
a. Mary kicked the ball to the fence.
b. John pushed the desk to the wall.
c. Sue slid the paperweight to the edge of the table.

In these cases, the transitive verb always denotes an action performed on the direct-object's referent, and the to-PP always adds the information that the object of to denotes the new location at/near which the direct object referent ends up as a result of the action performed on it. Such examples can readily be constructed with hundreds of transitive verbs of motion.

But $(9 a)-(9 c)$ are semantically different from the above:
a. Mary explained the memo to John.
b. Mary rented the apartment to John.
c. John offered a glass of tomato juice to Mary.

(9a) does not mean that the memo itself came to be at/near John, but only that the information contained in the memo came to be more fully understood by John, as a result of Mary's explanation. In (9b), however, neither the apartment nor its "semantic content" changes location: rather, because the verb is rent, we understand that a kind of temporary ownership of the apartment is acquired by John (subject to the conditions of the rent agreement). With offer, neither the glass of tomato juice nor its ownership changes location or possession - what happens is that Mary acquires the option to acquire possession of of the tomato juice, if she so chooses.

Examples of such "ambiguity" can be reproduced with many other prepositions (locative remove it from the table vs. non-locative learn it from the doctor), and in other languages. We want to reexamine it here in detail anyway, to delve into the reasoning behind the two bestknown ways to try to solve it.

of type raising). More simply, we can call the lowest type to which $\alpha$ belongs the lexical type of $\alpha$, specify that the definitions of head, complement and adjunct apply only to phrases occurring in their lexical types. type-raised phrases can also be distinguished from subcategorized adjuncts by the form of their semantic interpretation:

Type Raising of $\alpha: \quad \alpha^{\prime} \Rightarrow \lambda f\left[f\left(\alpha^{\prime}\right)\right]$

Adjunct reanalysis of $\alpha: \quad \alpha^{\prime} \Rightarrow \alpha^{\prime \prime}, \quad \alpha^{\prime \prime} \neq \lambda f\left[f\left(\alpha^{\prime}\right)\right]$ 


\section{Dual Analysis of Adjuncts/Complements}

\subsubsection{First Approach: "Abstract Thematic Roles"}

Gruber (1965), Jackendoff (1972) (and later papers by Jackendoff), Fillmore (1968), and others urged us to analyze the preposition meanings in (8) as well as (9) so that all signify the same thematic role (or abstract deep case), called GOAL. The meaning of GOAL is broad enough to represent both literal change in physical location (directional) in (8), and abstract change in some property not involving literal motion, thus no ambiguity in to need be postulated at all. The same is done with SOURCE and LOCATION, so all non-locative "changes of state" marked by preposition are reduced to abstract versions of locative prepositions; this approach has been called the 'Localist Hypothesis' by Anderson (1971))

This idea gained widely support. But what Gruber and Jackendoff do not ever fully explain to us is how, exactly, the semantic component of the grammar determines which kind of meaning GOAL has in which example. After all, kick the ball to the fence cannot mean that the fence acquires possession of the ball, any more than (9a) can mean that the memo itself moved to John's location.

The situation is actually worse than this: the various abstract instances of GOAL differ semantically from each other in unpredictable ways. With explain, the GOAL apparently means "transfer of the information contained in something to NP, but in a more intelligible form.'. With rent does not mean "transfer the information in the apartment", nor conversely can GOAL with explain refer to a change in possession of (something). With offer, GOAL refers to a transition in an option to acquire, but neither a transfer in information content nor a change in possession. (There are even examples of to that don't refer to a transition into a state at all, but rather the avoidance of such a transition: refuse a hearing to the prisoner, deny requests to all of them.

Thus (as has been recognized by the critics of Jackendoff and Gruber for some time), the abstract element GOAL is not really a semantic element that can play any consistent, useful part in the compositional semantics of all sentences involving to: GOAL is merely a label for a class of cases which may intuitively seem somehow related, but for which we still do not have a real semantic analysis.

\subsubsection{Second Approach: Ambiguity between Adjunct and Syntactic Marker}

Logicians, and many semantically conscious linguists, have long regarded the various nonlocative occurrences of prepositions as purely grammatical markers, with the verb of the sentence being the sole semantic source of the multi-place relation being expressed: Mary gives the book to John is thus represented logically using a 3-place relation give:

\section{$\operatorname{give}(\mathbf{m}$, the-book, $\mathbf{j})$}

A currently popular syntactic implementation, then, is to postulate an ambiguity in every relevant preposition (to, from, at; off of, on, onto, etc.) between (i) a meaning-bearing literal locational preposition, and (ii) a syntactic artifact, a (semantically vacuous) idiosyncratic "case marker", "case marking preposition". This permits us to give a correct account of sentences with non-locative PPs, but it is ultimately satisfactory?

Note that this approach fails to make any connection in the grammar or semantics between locative to and abstract "dative" to, between locative from and abstract "Source"; it leaves it entirely as a grammatical accident that example after example of prepositions and morphological 


\section{David Dowty}

cases, in language after language (though not in every language), shows this synchronicity. ${ }^{7}$

Ultimately, this connection must have its origin in the psychology of language acquisition or cognition itself: Clark \& Carpenter (1989) show that many English-speaking children make several systematic "errors" in acquiring the ways that "Source" is expressed in English, which taken together, imply unmistakably that children are at some stages working with an underlying concept of "Source" of just the Gruber-Jackendoff kind.

\subsubsection{The Dual Analysis: Case-Marking-to as a Reanalysis of directional Adjunct-to}

Is there no way to better describe the case-localist connection in terms of grammar, or must grammar theorists sit back until some other field (psychology of language?) solves this difficult problem? In fact, I think we can improve on the formal theoretical side of the problem significant, and the first important step is the DUAL ANALYSIS HYPOTHESIS.

The idea behind the dual analysis view can be thought of (for now, anyway) as the claim that the locative adjunct analysis of all occurrences of to, from and other locative prepositions is a PRELIMINARY ANALYSIS which serve language-learners as a semantic "hint" or "crutch" to figuring out the idiosyncratic correct meaning of the complement analysis for the non-locative instances: a preliminary adjunct analysis of the to-PP ( as locative) (10a) gives way to a complement analysis of to-PP structure as in (10b:)

\section{a. adjunct structure:}

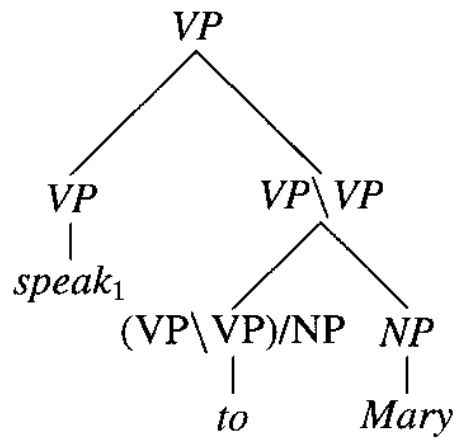

b. complement reanalysis: ${ }^{8}$

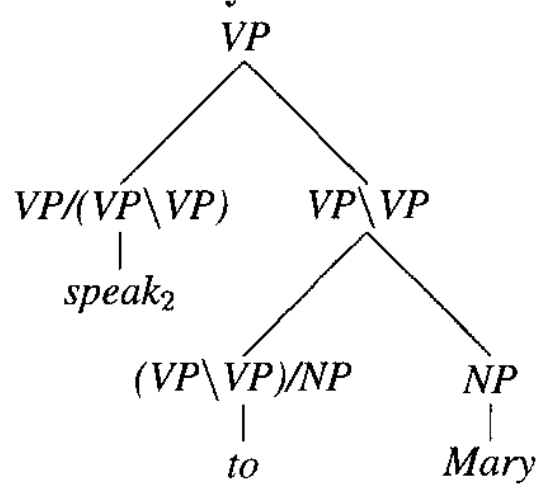

Sem: $\operatorname{speak}_{2}^{\prime}\left(\right.$ to $\left.^{\prime}\left(\mathrm{Mary}^{\prime}\right)\right)$

Sem: $\left(\right.$ to $^{\prime}($ Mary $\left.)\right)\left(\right.$ speak $\left.k_{1}^{\prime}\right)$

\footnotetext{
${ }^{7}$ Finnish, a non-European language, would at first seem devoid of this kind of connection, since it has three complete sets of four kinds of cases (which replace prepositions in that language): one set relating to enclosures (for "out of", "in", and "into"), a parallel set for surfaces ("off of", "on", "onto"), a third set relating to proximate location ("at/near to","away from", etc.) and a fourth, (morphologically distinct) set for abstract, non-locative transitions (non-locative Source, State, and Goal). However, it turns out that this last set is historically derived from an older set of case markers which signified locative transitions, before the first three sets came into the language. So even Finnish, though its history, reveals the same deeper connection between Local and corresponding NonLocal case marking as seen elsewhere.

${ }^{8}$ Although this structure is actually perfectively adequate for both the semantics and syntax of complement reanalysis, there is no reason why it could not be further simplified, if desired, to replace the adjunct category $V P \backslash V P$ with a simple, non-adjunct category like $P P$-i.e. $s p e a k_{2}$ would also belong to $V P / P P_{[\text {тол] }}$ here, and to to $P P_{[\mathrm{TоO}]} / N P$, with to translating as the identity function, insofar as its adjunct meaning is otiose.
} 


\section{Dual Analysis of Adjuncts/Complements}

The semantic interpretation of John speaks to Mary, under the adjunct analysis as in (a) is "John speaks, and the result of this action is that John ends up in a location next to Mary"-not the real intended meaning of the sentence of course, but a rough "hint" for the learner who has not grasped the "speak-to" construction. Note that in the complement interpretation of speak $k_{2}$ (in (b) ) cannot be the same as speak in (a): rather, it takes the change-of-place to-"adjunct" as its semantic argument, and its meaning is something like "speak, with the intention that the verbal content of what one is saying will end up at a certain place (to-Mary) and will be understood there)"; in other words, the proper way to interpret to Mary here is now built into the meaning of speak $_{2}$.

\subsection{The Cognitive 'Trade-Off' between Adjuncts and Complements}

But why should languages really need an adjunct analysis as a "preliminary step" toward a complement analysis, anyway? If we step back and reflect on the communicative advantages of each, vs. the language-learning advantages of each, we can see that there is a trade-off between the two analyses.

- If we focus on the effort required from the learner of a language, then a adjunct analysis offers the advantage of yielding more 'quasi-multi-place predications at a lesser load on lexical memory - because they are semantically compositional. Suppose the lexicon of a language has $n$ different intransitive verbs (say, 100 verbs) and $m$ different prepositions that can form adjuncts (say ten prepositions), then compositional syntactic and semantic rules automatically produce $(n \times m)$ different two-place predications $(=10,000$ in this case), all of which have distinct meanings. By contrast, if the learner had to express all these two-place predications by learning individual transitive verbs, she would need to learn 10.000 different lexical items. But adjunct analyses achieve this advantage at the cost of a limition on the range of meanings that can be expressed:

- If we focus on the semantic expressivity of the language, then lexical two-place predicates (verbs taking an object as well as subject) have an advantage over two-place predications derived by adding adjuncts: Though there may be $10,000(m \times n)$ of the adjunct-dereived meanings, these meanings are all limited (in a way that the lexical meanings are not) to what is produced by a consistent compositional semantic rule that combines a verb meaning with a preposition meaning. ${ }^{9}$ Lexical two-place predicates are not limited to these, rather, one verb can express ANY imaginable(humanly 'processable') semantic two-place relations Thus we achieve greater expressivity at the cost of a larger burden for the language learner.

This is just the trade-off we saw with to: we can compositionally generate lots and lots of adjunct-derived locative two-place semantic relations with little effort (walk to, drive to, swim to, walk from, drive from, swim from, etc. but none of these can correctly express the semantic relation lexicalized in speak to, rent to and offer to, which instead must be learned as individual items. However, by allowing the language learner to access the adjunct analysis as a fruitful preliminary "clue", one would soften the learning burden. If some multi-place relations like

\footnotetext{
${ }^{9}$ This claim about expressive advantages of complements actually only follows if we make some further (plausible) assumptions about how adjunct meanings work; see also $\S 7$ below, but see Dowty (2000) for details.
} 


\section{David Dowty}

speak to, rent to look superficially the same as an adjunct structures, then the learner will be led through the preliminary step automatically.

This "trade-off" may not be a very earth-shaking idea for locative-to vs. "dative" $t o$, but note that my claim here is that this same trade-off applies to ALL parallel cases of an adjunct vs. a superficially similar complement - for example, infinitive adjuncts of intransitives (e.g. sing to please Mary) vs. infinitive compliments (try to please Mary), and the dozens of other cases in $\S 5$.

\subsection{A Second Case Study: Agent Phrases in Passives}

In the case of the dual analysis just discussed, individual verbs differ fairly sharply as to whether they ultimately take adjunct or complement to. In other cases to be discussed below, a single verb may still permit, in "adult" speech, both an adjunct reading and a complement reading equally, or else a whole construction may prefer the adjunct reading almost exclusively, or the complement reading almost exclusively-the last possibility being illustrated by agent phrases in passives. My proposal is that all these posssibilities should to be treated formally via dual analyses, with it being left to psycholinguistics to determine exactly how these cases differ in mental processing.

The agent phrase of a passive (by Mary in John was visited by Mary) has been frequently analyzed as an adjunct, but just as frequently analyzed as an instance of "prepositional case marking", i.e. the by-phrase is a complement of the passive verb, but by has no independent meaning of its own, it is merely the marker that passive verbs subcategorize for. The dual analysis of by-phrases will provide a second useful case study, because it differs from the dative to-phrase in several ways; notably, it involves a syntactic/morphological construction, not just single verbs, and more importantly, it shows how the dual analysis is motivated by diachronic and typological facts, not just "thought experiments" in language acquisition.

One reason to suspect that passive agent phrases are possibly adjuncts is that the meaning borne by the $b y$-phrase in a passive, as in (11) seems intuitively very similar to that of other byphrases as in (12) that do not accompany a passive verb and hence must necessarily be analyzed as adjuncts:

\section{(11) John was touched by Mary}

(12) This book is by Frege.

A dress by Chanel.

She sent him a letter by courier.

He washed the dishes by hand.

She died by her own hand.

cf. Cheating by students is punishable with expulsion. (Keenan (1985): NB cheating here is not from a passive verb.)

Note the by-phrases in (12) all seem to entail a semantically-related sentence that is a true passive: for This book is by Frege, compare "This book was written by Frege"; for She sent him a letter by courier compare "A letter was delivered by courier", and so on.

Nevertheless, it has been recognized in the semantics literature for some time that a semantically correct adjunct analysis of agent phrases in passives is either impossible or else very 


\section{Dual Analysis of Adjuncts/Complements}

difficult (and has not been achieved in any case; cf. Thomason (1974), Cresswell (1985), Dowty (1979). For one thing, pairs like (13) show that an adjunct analysis cannot be extensional but must be handled intensionally in some way, while a complement analysis never requires this complication:

(13) This chair was sold to Mary by John.

This chair was bought from John by Mary.

(See the above-cited references and Dowty (1989) for explanation.) It is now widely held that a "Neo-Davidsonian" analysis in terms of events can circumvent this problem (cf. Parsons (1990), but as argued in Dowty (1989) and Dowty (2000), this will not really work. This approach appeals to an abstract Thematic Role 'AGENT', but this fails for the same kind of reason that we saw with GOAL earlier: there is no possible semantic definition of AGENT that is independent of the particular verb that it occurs with. Notably, passives of stative verbs occur with agent phrases (in English and other languages), but these are not "Agents" in a semantic sense, rather they are "Experiencers":

(14) This rumor has now been heard by almost every voter, and it is believed by many of them.

The only correct way to identify what the by-phrase refers to here is to appeal to the meaning of the active verbs hear and believe, not via semantics, and this demands a complement analysis of the by-phrase.

The account in terms of a dual analysis begins with the assumption (well-justified by crosslanguage typological studies) that the agentless passive is the most basic form of passives they occur in more languages than agentive (or "full") passives occur in, while there are no languages with only the agentive passives but no agentless passives. The agentless passive can be analyzed adequately and very simply as a detransitivizing, "relation-reducing" operation on transitive verbs:

(15) Passive as a detransitivizing operation:

(Agentless) Passive:

$\begin{array}{lccc}\text { Lexical Rule: } & \alpha \in v p / n p & \rightarrow & \text { PST-PRT }(\alpha) \in v p_{[\mathrm{pp}]} \\ \text { Semantic Interpretation: } & \alpha^{\prime} & \rightarrow & \lambda x \exists y[\alpha(x)(y)]\end{array}$

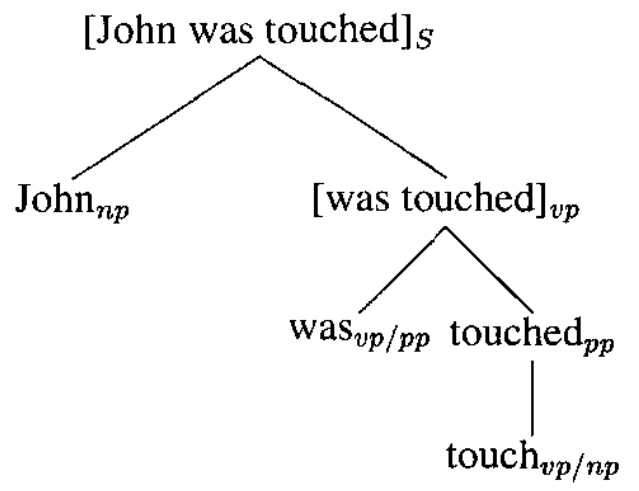


(17) Translation of $((17)): \quad \exists x\left[\operatorname{touch}^{\prime}\left(\mathbf{J o h n}^{\prime}\right)(x)\right]$

Assuming that by-phrase agents (as in (13) above) exist in the language already, then the meaning of a "full passive" can be approximated, without any addition to the syntax, by adding a by-phrase adjunct to an agent-less passive:

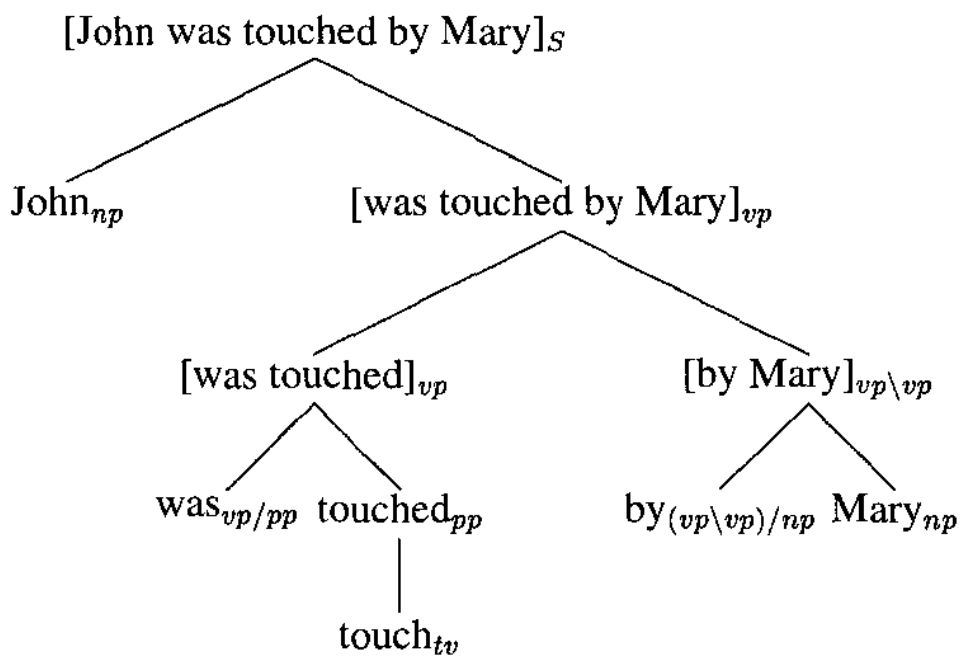

(19) Translation of (18):

$\mathbf{b y}^{\prime}\left(\mathbf{M a r y}^{\prime}\right)\left(\lambda y\left[\exists x \operatorname{touch}^{\prime}(y)(x)\right]\right)($ John')

"John was touched, and Mary was a causal factor in this event"

As the paraphrase in (19) suggests, the meaning of $\mathbf{b y}^{\prime}$ here, which is the adjunct meaning, does not produce the correct meaning of the actual English passive sentence but only approximates it, and of course it also cannot possibly serve as the final analysis of full passive for the reasons cited above (and it is important to note in this regard (cf. below) that many languages exist in which agent phrases are not found with passives of stative verbs, only active verbs). And so, I argue, the adjunct analysis serves as a preliminary step through which the complement analysis is reached. That analysis is:

(20) (Reanalyzed) Passive (as yielding 2-place predicate): ${ }^{10}$

syntactic rule: $\alpha \in v p / n p \rightarrow$ PST-PRT $(\alpha) \in v p_{[\mathrm{pp}]} / n p_{[+\mathrm{BY}]}$

semantic rule: $\quad \alpha^{\prime} \quad \rightarrow \quad \lambda y \lambda x\left[\alpha^{\prime}(x)(y)\right]$

. In this rule, $P P$ stands for the category of past participles (semantically the same type as the $V P$ category), and I have incorporated the further simplification of the category of passive touched from $P P /\left(V P b a c k s l a s h V P\right.$ ) to $\left.P P / N P_{[} b y\right]$ (see footnote 8 ).

\footnotetext{
${ }^{10}$ In this rule, and in the example tree below, I have already incorporated the secondary simplication mentioned in the previous footnote, i.e. from $P P /(V P \backslash V P)$ to $P P / P P_{[\mathrm{BY}]}$
} 
(21)

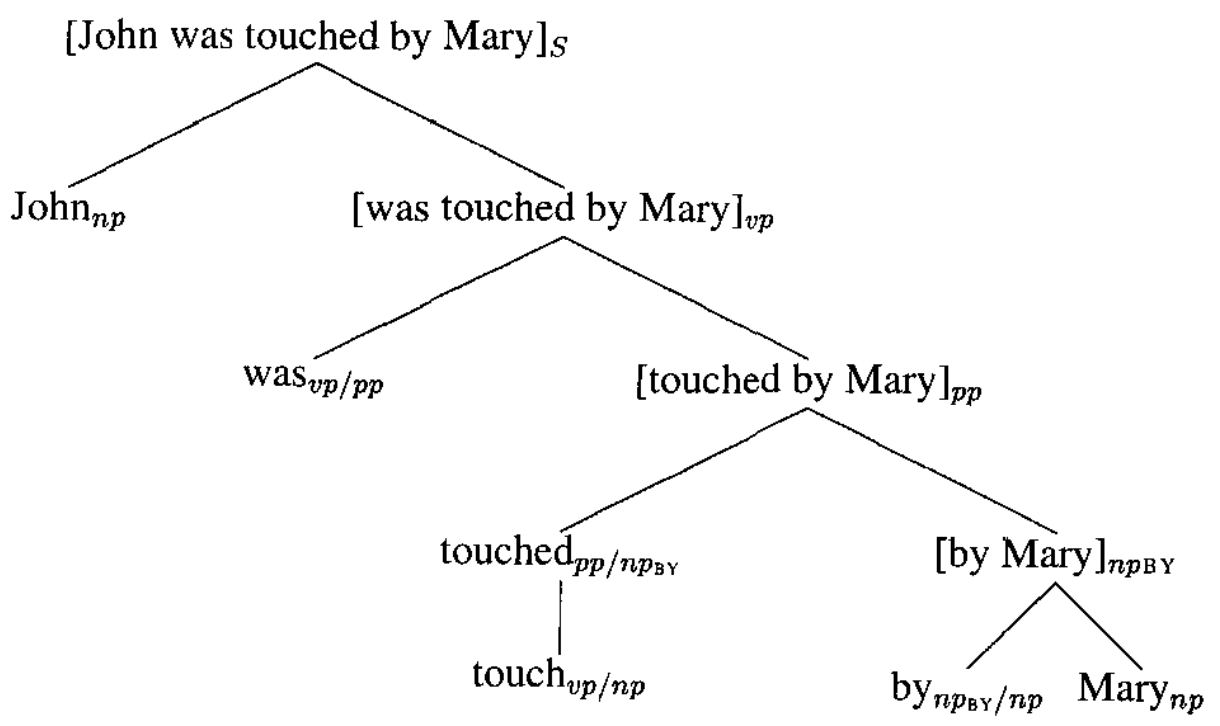

(22) Transl. of (21) is equivalent (by $\lambda$-conversion) to: $\quad \operatorname{touch}^{\prime}\left(\mathbf{J o h n}^{\prime}\right)\left(\mathbf{M a r y}^{\prime}\right)$

For passive agent phrases, typological data about the distribution, form, and semantic restriction on agent phrases cross-linguistically, imply that there are observable diachronic manifestations of the reanalysis hypothesis as just sketched above. The following typological generalizations about passive agent phrases were observed in (Keenan 1985:247)

(23) a. Some languages exist in which only agentless passives occur, though no languages apparently exist in which agentive passives occur but no agentless passives.

b. In many languages, passives of stative and other "not highly transitive" verbs are ungrammatical.

c. Either instrumental case or a preposition with instrumental meaning is (almost) always used to mark the agent of a passive in natural languages, according to Keenan (1985:261). (Actually, it seems that prepositional phrases with "Source" meaning sometimes appear instead, e.g. English from, German von)

These typological generalizations are just what we would predict if the dual analysis/reanalysis of agent phrases is given the following diachronic interpretation, as seven (possibly hypothetical) stages in the development of passives in a language:

Hypothesized stages in the development of passives with agent-phrases:

1. Passive is a "relation-reducing" (or "detransitivizing") rule (Dowty 1982a). Only the 'agentless forms' of passive sentences appear in the language; what will become agent phrases (by-phrases, in English) only occur as instrumental adjuncts of nonpassive VPs (send the package by airmail or the like). 


\section{David Dowty}

2. Agent Phrases occur as adjuncts (with instrumental/source meaning) to passive verbs; as instrumental "agent phrases" would not make sense with stative and other non-volitional and non-causative passive verbs, agent phrases never occur with them.

3. Agent-phrases are reanalyzed as complements of passive verb phrases, thus leading to step 4:

4. The agent-phrase-marking preposition (by in English) or instrumental case marking is reanalyzed as a marker of grammatical function (without independent semantics), a so-called "case-marking" preposition or "empty case" and does not contribute any meaning per se to the compositional semantics of the sentence.

Passive is now an argument-permuting rule ("relation-changing" rule), i.e. one that yields the same 2-place lexical meaning as the active verb but with subject and non-subject arguments interchanged.

5. Passives of stative verbs, other non-causatives, etc. now occur.

\section{Syntactic Consequences: Predictions about Word Order of Adjuncts vs. Complements}

In English and typologically similar languages, adjuncts in general can often occur at various positions within the clause, while superficially similar complements have a more restricted position-specifically, complements in English always follow verbal heads. For example:

\subsection{Infinitive Adjuncts vs. Infinitive Complements}

a. John sang to please Mary (to please Mary is adjunct)

To please Mary, John sang

John, (in order) to please Mary, sang for hours.

b. John tried to please Mary (to please Mary is complement)

*To please Mary, John tried

*John, (in order) to please Mary, tried for hours. $\quad$ (acceptable only if tried is taken to have an elliptical complement)

\subsection{Subcategorized Adjuncts}

Subcategorized adjuncts, such as adverbs, are distinguished from true adjunct adverbials in just this way:
a. They criticized him harshly
(adjunct)
They harshly criticized him
b. They treated him harshly
*They harshly treated him ${ }^{11}$
(subcategorized adverb)




\section{Dual Analysis of Adjuncts/Complements}

Allowing multiple syntactic positions for adjuncts can be done in various ways in CG; one way is to give adjuncts multiple category membership (e.g. $S / S$ vs. $S \backslash S$ ), another is to introduce them as "permutable" constituents within a multi-modal CG allowing adverbs to obey the logic of LP. But once we observe the (independently verifiable) typological demand in English that complements always follow their heads, then the implication for adjunct reanalysis is this:

- An adjunct can be reanalyzed as a complement (in English) only when it follows its head; the same adjunct in any other syntactic position cannot be reanalyzed.

\subsection{Position of repetitive vs. restitutive again (wieder)}

At this point it is interesting to look at the word order possibilities for the repetitive (external) reading of English again and German wieder vs. those for the restitutive (internal) again and wieder (Dowty 1979), (Fabricius-Hansen 1983). (This ambiguity is present in a sentence like Mary shook John awake again: the external (or REPETITIVE) reading entails that this was the second time that Mary had shaken John awake; the internal (or RESTITUTIVE) meaning only entails that John became awake for a second time as a result of Mary's shaking him, not that she shook him for a second time, i.e. Mary has merely restored the state of John's awakeness.) Dowty (1979:260-264) proposed that this meaning difference results from a complement vs. adjunct ambiguity (an ambiguity in the verb's category), not an ambiguity in the adverb per $\mathrm{se}^{12}$, so this predicts that the availability of both readings will depend on word order. FabriciusHansen (in the cited paper and elsewhere) and others have argued for a different analysis of this ambiguity, thus not immediately predicting any word order sensitivity.

In fact, the two readings are indeed limited by syntactic position, just like infinitives and subcategorized adverbs (treat harshly). When again occurs to the right of the verb, both readings for again are available; in any other position, only the external (repetitive) reading exists:

a. Mary shook John awake again (Both readings)

b. Again, Mary shook John awake (Only repetitive reading) Mary again shook John awake. (Only repetitive reading)

c. When the power failed, the satellite entered the atmosphere again. (Both readings)

\footnotetext{
${ }^{11}$ Mike Calcagno has observed the paradigm below, which shows in more detail that this restriction cannot be an artifact of the particular choice of adverb; rather treat (in this sense) requires an adverb complement on its right, and a pre-verbal adverb cannot satisfy this subcategorization requirement:

(27) a. They treated him harshly. They treated him cruelly

b. They harshly treated him cruelly They cruelly treated him harshly

c. *They harshly treated him. *They cruelly treated him.

${ }^{12}$ It should be noted that Dowty (1979) actually proposed TWO analyses of this adverb problem; in addition to the complement/adjunct analysis (pp. 260-264), another analysis was entertained (pp. 264-269) that attributes the ambiguity to the category of the adverb; subsequent examination showed that the complement/adjunct analysis is the more viable one.
} 
d. When the power failed, the satellite again entered the atmosphere. (Only repetitive reading)

Arnim von Stechow ((von Stechow 1996) and p.c.) has noted that the restitutive reading of wieder in German is only available when wieder appears in a syntactic position where a verbal complement can appear in in German, while the repetitive reading is available for wieder in any position German allows for an adverb. Thus for both English and German, the syntactic prediction of the reanalysis hypothesis are met for again (wieder). See Dowty $(1979,1993$, to-appear) for more data and details.

\section{Independent Arguments for the Simultaneous Existence of Multiple Syntactic Analyses: The Perspective of Historical Linguistics}

The postulation of simultaneous multiple analyses has often been regarded with suspicion within the methodology of modern linguistic theory - a sign of a "missing generalization" at least, and always deemed inferior to a proposed alternative that appeals only to a single analysis.

In spite of this, several papers over the years have argued explicitly for multiple syntactic analyses, even when there is little or no detectable accompanying semantic ambiguity. A few of these are:

- Hankamer (1977), "Multiple Analyses"

- Kroch (1989) "Reflexes of Grammar in Patterns of Language Change"

- Ladusaw \& Dowty (1988), Bresnan (1982a): 'Syntactic Control' of complements vs. 'RealWorld Control' of actions and objects: unexpected acceptability of He was promised to be allowed to leave

But many historical linguists have long accepted the idea that multiple analyses must be assumed to be available to a single generation of speakers in order to explain fully the facts of language change. One clear explicit statement of the reasoning behind this deserves quoting here, from A. Harris and L. Campbell, Historical Syntax in Cross-Linguistics Perspective, (Harris \& Campbell 1995:81, ff):

\subsubsection{Multiple analyses during actualization}

During the period of actualization, a single input structure continues to have multiple analyses in the grammar of the individual speaker. For descriptive purposes it is convenient to recognize three stages to reanalyses:

Stage A, Input: The input structure has all of the superficial characteristics of the input analysis.

Stage B, Actualization: The structure is subject to multiple analysis: it gradually acquires the characteristics of an innovative analysis, distinct from that of Stage A. 


\section{Dual Analysis of Adjuncts/Complements}

Stage C, Completion: The innovative structure has all of the superficial characteristics of the innovative analysis

Reanaiysis is the transition from Stage A to Stage B. Stage B is the period of actualization, and the speaker makes both (or many) analyses, which may be related to each other in different ways at different times. Stage B typically consists of multiple changes, reflecting the characteristics of the particular construction in the particular language. It may be noted that the gradualness of change is due in part to the duration of actualization in some changes. Some reanalyses may not reach Stage C; they are never completed, in the sense that all the characteristics of the innovative analysis may not be acquired.

It has often been assumed, especially in the description of change in individual languages, that in reanalysis the period of multiple analyses is only transient, and that the innovative analyses rapidly replaces the earlier analysis. There are at least three kinds of evidence that multiple analyses continue to be available in individual grammars for some time, though that time of course is different for different changes. Evidence comes from the possibility of multiple reflexes, from variation and conflicting data, and from the possibility of reversibility of change....

\section{Evidence for the Adjunct 'Origin' of Most Complements}

Probably one of the most compelling arguments for dual analysis in English comes from the very large set of pairs of cases where (i) an adjunct construction is found that parallels a complement construction exactly, at least in "surface" syntax, (ii) the two parallel constructions can be shown to have the same kinds of semantic similarities and differences between adjunct and complement already discussed above, and (iii) the same syntactic differences also occur (i.e. word order possibilities).

Because of space limitations, all I can do here is enumerate a representative list of these pairs, with examples for each pair: this is in Table 1 below.

It will have to be left as an exercise for the reader (i) to find more examples for each pair of constructions, (ii), to verify that the allowable word orders are usually broader for the adjunct than the complement case (iii) to figure out the (regular) adjunct meaning of each case, and (iv) to verify that the the "specialized" meanings of the complement examples do in fact differ (sometimes subtly) from the corresponding regular adjunct meaning.

The case of the complement vs. adjunct genitives is worth special comment, all the more so in this context because of the interesting connections between it and Partee and Borschev's paper on genitives in this volume. It has been widely recognized for years that possessives (and genitives) have a different semantic function when they combine with relational nouns (friend, mother, top, etc.) than with non-relational nouns (team, dog, table, etc.) This idea has been thoroughly investigated (independently) by Barker (1991), (1995) and by Partee (1997) (based on unpublished work by Partee from 1983 and developed in subsequent papers). The reading (normally) found with relational nouns (Mary's mother) is called LEXICAL, INTRINSIC (Barker) or INHERENT (Partee), and that with non-relational nouns (Mary's book is called EXTRINSIC (Barker) or FREE (Partee), or MODIFIER. The meaning of the extrinsic possessive is quite broad but is also context dependent - for example, John's team could mean, depending on the context in which it is uttered, either "the team that John plays on", or "The team that John owns", or "the team that John cheers for", or "The team that John placed a bet on today". The extrinsic/free 
Table 1: Table of Examples of Corresponding Adjunct vs. Complement in English

ADJUNCT CONSTRUCTION:

A1. Adjective Adjuncts to VPs John left work exhausted.

A2. Adj. Adjuncts to Transitive Verbs ${ }^{15}$ John ate the meat raw

A3. "Repetitive Again (Ajunct Again, Mary shook John awake

B1. Directional PP adjuncts to intr. Vs Mary walked to the park.

B2. Directional PP adjuncts to tr. Vs ${ }^{15}$ John threw a ball to the fence.

C. Instrumental with-adjuncts John swept the floor with a broom

D. Other intr. and tr. PP adjuncts

I took it from the box

E. Agent phrases of passives (early stage)

[ $=$ by-phrase as instrumental adjunct $]$

F1. 'Rationale' purpose infinitives John sang (a song) (in order) to impress Mary

F2. Gapless Object-controlled infinitive adjuncts $^{15}$

John hired her to fix the sink

G. Gapped non-subject-controlled infinitive adjuncts

Mary bought it to read _ on the plane.

H. Adjective-modifying gapped infinitive adjuncts

It is available to figure your tax with

I. Possessive adjuncts of nonrelational nouns

Mary's team (etc.)

A team (etc.)) of Mary's
CORRESPONDING COMPLEMENT

CONSTRUCTION:

\section{Adjective Complements to VPs}

John arrived alone.

Adj. Complements to Tr. Verbs ${ }^{15}$

John's attitude made Mary unhappy

"Restitutive" Again (Complement)

Mary shook John awake again

Dative complements to intro. Vs

John sang to Mary

Dative complements to Tr. Vs

John threw a ball to Mary.

John threw Mary a ball.

With-marked complements

John loaded the truck with hay.

Other intr. and tr. PP complements

I learned it from a doctor

Agent phrases of passives (final)

$[=b y$-phrase as complement of passive verb]

Infinitive complements of verbs

John attempted to impress Mary

Infinitive complements of transitives $\left.^{13} 14\right]$

John persuaded her to fix the sink

(None?)

\section{“Tough"-complements}

It is hard to figure your tax with _..

Possessive complements of relational nouns

Mary's mother (etc.)

the mother (etc.) of Mary 


\section{Dual Analysis of Adjuncts/Complements}

reading, it has been proposed, has a meaning such that Poss Noun is, uniformly "the unique Noun that stands in some contextually-determined but salient relation to Poss"; it is up to the hearer to figure out exactly what kind of relation is intended, though the relation of 'ownership' is probably the most common. If so, this extrinsic meaning can be semantically analyzed as an adjunct reading in my sense. The intrinsic/inherent possessive (Mary's mother, mother of Mary differs, in that the nature of the relation between Possessor and Noun is determined by the relational noun (so it is of course different for each relational noun). Thus in terms of this paper's hypothesis, the inherent genitive must be a complement of the relational noun, not an adjunct.

The syntax of these two kinds of possessives and genitives is different from the other complement/adjunct cases above: the pre-nominal possessive is the one case I know of where a complement can precede its head (in English), e.g. Mary's mother. But the two readings do differ syntactically in the post-nominal position, albeit in a subtle way: the so-called "double genitive", as in a book of Mary's is only found with extrinsic (adjunct) genitive meaning ${ }^{14}$ : note that \#The mother of Mary's sounds quite odd, which is because mother is relational. Conversely, the post-nominal genitive with no possessive suffix occurs only with inherent/intrinsic (relational) readings (The mother of Mary) and not with non-relational heads (\#A book of Mary sounds odd). (Cf. also Partee and Borschev's paper in this volume.)

The significance of all the cases A-I in the table above can be summarized this way: If it is important to the grammatical structure of a language, (and important to the learners of the language) to distinguish adjuncts from complements, why should the grammar of English have dozens of cases where an adjunct construction and a complement construction look superficially exactly alike? This seems rather counter-productive.

But, if it somehow helps the language learner that each complement construction should look so similar to an adjunct construction as to be initially "mistaken" for one, then this is exactly the distribution of data that we should expect!

\section{Dual Analysis is a more complex matter than just reanaly- sis in language acquisition}

We can better understand that there are broader implications of the dual analysis hypothesis by digressing for a moment to examine the semantics of compounding and other word formation rules.

\footnotetext{
${ }^{14}$ Barker (1998) argues that the "double genitive" is actually a partitive reading (a book of Mary's = "a book of Mary's books"); if so, this is not an extrinsic reading but nonetheless still not an intrinsic reading either, but my general point still holds that genitive complements to relational nouns are syntactically distinct from other post-nominal genitives. See also (Partee \& Borschev 1998).

${ }^{15}$ When examining all examples of adjuncts and complements to transitive verbs, it is important to keep in mind that I am assuming a WRAPPING analysis of direct objects (cf. Bach): thus what I call a complemnt (or adjunct) to a transitive will never appear immediately adjacent to the transitive, but rather after the direct object. Thus, the combination of persuade with its complement to leave form a DISCONTINUOUS CONSTITUENT in persuade Mary to leave
} 


\section{David Dowty}

\subsection{Compounds and derived words}

In the history of the study of compounding in generative transformational grammar, linguistic theory has alternated repeatedly between deriving compounds by grammatical rule ((Lees 1960), (Levi 1975)) and arguing that derived compounds are not derived grammatically but are only listed individually "in the lexicon"; the latter position is supported by pointing to the idiosyncrasies of the meanings of individual examples that cannot possibly follow from any general rules ((Chomsky 1970), and in a different sense, also (Downing 1977)). The mistake that I think has usually been made in this debate is the assumption that if compounds (etc.) are listed individually in the lexicon (together with their meanings), then there cannot also be a rule that derives meanings of compounds by general rule.

Instead, I believe that a speaker's knowledge of her/his language includes both ways of deriving meanings for most compounds. This is best shown with English Adjective-Noun compounds. I propose that all English speakers know that any compound of the form "Adj-Noun" has associated with it a 'general', rule-predictable meaning paraphrasable as "Noun that is Adj". Thus a blackberry must be "a berry that is black", a bluebonnet is "a bonnet that is blue", and so on. But at the same time, speakers are perfectly aware that "berry that is black" (etc.) is not the real meaning of blackberry; that is rather "a certain species of bush that produces edible black, tiny berries in clusters." Other examples:
example:
predictable meaning:
real meaning:
a. big shot "shot that is big"
important or influential person
b. blackboard "board that is black"
surface made for writing on with
chalk, often black in color
c. quicksand "sand that is quick"
fine sand mixed with water that sucks down an object resting on its surface

To deny that speakers know there is some elementary sense in which soft drink means "drink that is soft" is to deny an obvious facet of speakers' knowledge of their language, notwithstanding the fact that they also know a "real" or "correct" meaning for such compounds.

Why should languages have such double meanings for compounds? With only a moment of reflection, the answer is obvious, I believe: the "predictable" meaning of a compound:

- gives the hearer a "clue" or "hint" to the compound's real meaning upon first encountering the compound

- serves as a mnemonic for more easily retrieving that real (and individually learned) meaning from memory when the compound is encountered again later

(Try as a mental exercise to imagine what English would be like if all compounds were replaced by mono-morphemic words that had to be learned individually, without any morphological clues: English would be far harder to learn!.)

On encountering the compound software for the first time, a speaker at least has a clue from its derivational meaning ("wares that are soft") where to start guessing what the real meaning might be. That is, one does not necessarily assume for a initial period of time that it really literally means "ware that is soft" and then correct that assumption later: more likely, a person realizes already at first hearing that software must have a much more specific, probably technical meaning. 


\section{Dual Analysis of Adjuncts/Complements}

What exactly is the relationship between the two meanings of a pair in the speaker's mind? What should it be in a linguist's grammar? The first question is no doubt highly interesting for psycholinguistics and the psychology of memory, but I doubt that much can be specified about this relationship in linguistic theory - nor should we try to. What we can and should do is simply specify that there are two kinds of meanings for each: (i) a predictable but only approximate meaning (and the rule that gives it from the meanings of the parts), and (ii) an individually-learned meaning for it-just like the individually-learned meanings of all monomorphemic words.

Other kinds of derivational word formation also show the need for dual analysis: it is intuitively felt by all speakers of English that all derivations of VERB + -able have a uniform approximate meaning: "capable of being verb+ed" - so that washable means "capable of being washed". At the same time, speakers know that many such forms have a more specific actual meaning: readable does superficially mean "capable of being read", but its actual meaning is something more precise. ${ }^{15}$

My general point in making these observations about word formation is to argue that the two analyses in each word formation "dual" are almost certainly not simply a matter of the lexicalized analysis replacing the preliminary analysis, then disappearing forever; rather the preliminary, semantically compositional analysis is still employed, in some subtle psychological way, in on-line processing - though in a way that only connectionism or some other other future theories of the psychology of language can explain.

If this is plausible, then simultaneous on-line processing is just as plausible for the "dual" complements-adjunct analyses.

So what the dual analysis hypothesis accomplishes (for both domains) is to allow theorists to formalize-right now-the two "endpoints" of a complex psycholinguistic "continuum".I have argued that being able to acknowledge and isolate these "endpoints", within a formal linguistic theory, improves our understanding the phenomena of "adjunct" and "complement".

\section{Remaining Problems: Further Limiting the Semantics of Adjuncts}

It can been shown that my proposal about the cognitive "trade-off" (discussed above) make some further formal limitation on adjunct meanings beyond that which is implicit in the standard semantic interpretation of the CG category $A \backslash A$, specifically in the case of $V P \backslash V P$. Logicians and some linguistic semanticists have traditional treated most adjectives and adverbs as one-place predicates (a Republican senator is simply anyone who is both a Republican and also a senator), hence the compositional semantic rule for Adj-N or for VP-Adv must be "intersection of two predicates". But Montague and others in the 1970's observed many examples of "intensional" modification (former wife, alleged communist, putatively spies on us),

\footnotetext{
${ }^{15}$ In their book On the Definition of Word, Di Sciullo and Williams (DiSciullo \& Williams 1987) introduce the term listeme for linguistic units that are thought to be "listed individually"(as opposed to generated 'on-line'): their listemes include all root morpheme, most derived words, certain syntactic phrases (idioms, and probably collocations) and a few sentences. Although this term does seem to draw the same distinction I am making here, Di Sciullo and William go on to deny that their 'listemes' have any relevance to linguistics at all, much less do they even raise the possibility of dual analyses for any one form, morphological or syntactic. Hence, I will not adopt their term 'listeme' here.
} 


\section{David Dowty}

and observed that the type assigned by Montague to VP $\backslash$ VP (and other instances of $A \backslash A$ ), "functions from properties (of individual) to sets (of individuals" was inherently rich enough to cover both intensional modification and ordinary intersective modification; following Parsons (1980), we can just translate any extensional modifier in category $A \backslash A$ with a lambda expression $\lambda P\left[\alpha^{\prime}(x) \wedge P(x)\right]$, using an extensional predicate $\alpha^{\prime}$. Inasmuch as non-intersective (intension) modifiers are the exception and intersective modifiers are the rule, this strategy could be criticized as "generalizing to the worst class", as some of his other analyses have been criticized, but it has nevertheless been judged adequate and accepted in CG up to the present, even though there is minor "inconvenience" in unifying the predicate with the attributive syntax of each extensional modifier (e.g. The woman is clever vs. The clever woman).

However, Kasper (1997) has discovered a more serious problem for this analysis of adjunct semantics, this time with the recursive use of intensional and extensional modifiers, that shows that Montague's categorial solution must ultimately fail, for compositional semantic reasons ${ }^{16}$ The ultimate solution, I argue in the successor to this present paper (Dowty 2000), is to go beyond the Lambek Calculus (L) and its relatives by adding a new kind of type constructor for intersective, extensional modifiers in $\mathrm{CG}$ (type logical grammar). We still want to retain the type $A / A$ for the non-intersective modifiers, as syntactic differences exist between between this and the intersective adjunct category (type). ${ }^{17}$

\section{References}

ANDERSON, JOHN M. 1971. The Grammar of Case: towards a localistic theory, volume 4 of Cambridge Studies in Linguistics. Cambridge: Cambridge University Press.

BARKer, Chris, 1991. Possessive Descriptions. University of California Santa Cruz dissertation.

—. 1995. Possessive Descriptions. CSLI Publications.

1998. Partitives, double genitives, and anti-uniqueness. Natural Language and Linguistic Theory 16.679-717.

BRESNAN, JOAN. 1982a. Polyadicity. In The Mental Representation of Grammatical Relations, 149-172. MIT Press.

CARpenter, Bob. 1997. Type-Logical Semantics. Bradford Books. MIT Press.

CHOMSKY, NOAM. 1970. Remarks on nominalization. In Readings in English Transformational Grammar, ed. by Roderick Jacobs \& Peter Rosenbaum, 184-221. Ginn and Company.

\footnotetext{
${ }^{16}$ This may not be immediately obvious from Kasper's paper itself, since it is couched entirely within HPSG syntactic terminology and HPSGs less rigid relationship between syntax and semantics, not the type-logical, syntaxdriven semantics of CG.

${ }^{17}$ In Dowty (1997) ("Adjunct to Argument Reanalysis... the Problem of Prepositional Phrases" - Blaubeuren 1997 Workshop Paper), I argued more specifically that (i) my claim that prepositional phrase complements and most other $V P$ complements are 'expressively richer' semantically than any possible VP adjuncts is really only valid if most such adjuncts are extensional intersective modifiers, and that specifically (ii) locative, directional, instrumental, etc. $V P$ adjuncts are in fact intersective modifiers of events (contra Keenan \& Faltz (1985)).
} 
Clark, Eve V., \& Katherine L. Carpenter. 1989. The notion of source in language acquisition. Language 65.1.1-30.

Cresswell, M. J. 1985. Adverbs and Events, volume 28 of Studies in Linguistics and Philosophy. Dordrecht: Kluwer.

DiSciullo, ANNA-Maria, \& EDWIN Williams, 1987. On the Definition of Word. LInguistic Inquiry Monographs 14. Boston, Massachusetts: MIT Press.

Downing, PAMELA. 1977. On the creation and use of English compound nouns. Language $53.810-842$.

DowTY, DAVID. 1982a. Grammatical relations and Montague grammar. In The Nature of Syntactic Representation, ed. by Pauline Jacobson \& Geoffrey Pullum, 79-130. Reidel.

- 1989. On the semantic content of the notion "thematic role". In Properties, Types and Meanings: vol. II, ed. by Gennaro Chierchia Barbara Partee \& Ray Turner, 69-130. Kluwer.

- 1996. Non-constituent coordination, wrapping, and multimodal categorial grammar. In Structures and Norms in Science, ed. by et al Dalla Charia, M.L., Proceedings of the 1995 International Congress of Logic, Methodology, and Philosophy of Science, Florence, 347368 .

- 1997. Adjunct-to-argument reanalysis in a dynamic theory of grammar: the problem of prepositions. Paper presented at the Blaubeuren Semantics CCG/adj-arg/onference, University of Tübingen, March 2, 1997.

$\ldots, 2000$. Adjuncts and complements in categorial grammar. (in preparation).

DowTY, DAVID R. 1979. Word Meaning and Montague Grammar, volume 7 of Studies in Linguistics and Philosophy. Dordrecht: Reidel.

FABRICIUS-HANSEN, CATHRINE. 1983. Wieder ein wieder? zur semantik von wieder. In Meaning, Use and Interpretation of Language, ed. by C. Schwarze R. Bauerle \& A. von Stechow, 97-120. de Gruyter.

FILlmore, CHARLES. 1968. The case for case. In Universals in Linguistic Theory, ed. by Emmon Bach \& Robert T. Harms, 1-90. Holt, Rinehart and Winston.

Gruber, Jeffrey S, 1965. Studies in Lexical Relations. Cambridge, Massachusetts: MIT dissertation. Published in revised form in Gruber 1976.

HANKAMER, JoRGE. 1977. Multiple analyses. In Mechanisms of Syntactic Change, ed. by Charles N. Li, 583-607. Austin: University of Texas Press.

HARris, Alice, \& Lyle CAMPBEll. 1995. Historical syntax in cross-linguistic perspective, volume 74 of Cambridge Studies in Linguistics. Cambridge: Cambridge.

JACKENDOFF, RAY S. 1972. Semantic Interpretation in Generative Grammar. MIT Press. 


\section{David Dowty}

KASPER, ROBERT, 1997. The semantics of recursive modification. unpublished paper, Ohio State University, Available from ftp://ling.ohio-state.edu/pub/kasper/jling-rev.dvi.ps.

KEENAN, EDWARD L. 1985. Passive in languages of the world. In Sytactic Typology and Linguistic Field Work, ed. by Timothy Shopen. Cambridge Uhiversity Press.

—, \& LEONARD M. FAlTZ. 1985. Boolean Semantics for Natural Language. Kluwer Academic.

KROCH, ANTHONY S. 1989. Reflexes of grammar in patterns of language change. Language Variation and Change 1.199-244.

LADUSAW, WILliaM, \& DAVID DOWTY. 1988. Toward a nongrammatical account of thematic roles. In Thematic Relations, ed. by Wendy Wilkins, volume 21, 62-74. Academic Press.

LEeS, RoBert B. 1960. The Grammar of English Nominalization. The Hague: Mouton.

LeVI, JUDITH N. 1975. The Syntax and Semantics of Non-predicating ADjectives in English. University of Chicago Dissertation.

Moortgat, Michael. 1998. Categorial type logics. In Handbook Of Logic And Language, ed. by Johan van Benthem \& Alice ter Meulen. Elsevier.

MORRILL, Glyn. 1994. Type Logical Grammar. Kluwer.

Parsons, TERENCE. 1980. Modifiers and quantifiers in natural language. Canadian Journal of Philosophy Supplementary Volume VI.29-60.

—. 1990. Events in the Semantics of English: A Study in Sub-Atomic Semantics, volume 21 of Current Studies in Linguistics Series. MIT Press.

PARTEE, BARBARA. 1997. Uniformity vs. versatility: the genitive, a case study. In Handbook of Logic and Language, ed. by J. van Benthem \& A. ter Meulen, 464 470. Amsterdam: Elsiever. (originally submitted in 1983).

—, \& VLADIMIR BORSCHEV. 1998. Integrating lexical and formal semantics: Genitives, relational nouns, and type-shifting. In Proceedings of the Second Tbilisi Symposium on Language, ed. by Robin Cooper \& Thomas Gamkrelidz, 229-241. Tbilisi: Center on Language, Logic, Speech, Tbilisi State University.

STEEDMAN, MARK. 1996. Surface Structure and Interpretation. Linguistic Inquiry Monograph No.30. MIT Press.

THOMASON, RICHMOND. 1974. Some complement constructions in Montague grammar. In Proceedings of the Tenth Annual Meeting of the ChicagoLinguistic Society, 712-722. Chicago Linguistics Society.

Venneman, Theo, \& R. Harlow. 1977. Categorial grammar and consistent vxserialization. Theoretical Linguistics 4.227-254.

VON STECHOW, ARNIM. 1996. The different readings of wieder'again" - a structural account. Journal of Semantics 13.87-138. 